\title{
Processo de cuidar da criança Queimada: vivência de familiares
}

\author{
Burnt children care procedure: experience in family \\ Procedimiento para el cuidado de los niños Quemados: experiencia en familia
}

\section{Milla Chianca Gomes Varela', Josilene de Melo Buriti Vasconcelos', Iolanda Bezerra da Costa Santos' , Ivanilda Lacerda Pedrosa', Alana Tamar Oliveira de Sousa'}

'Universidade Federal da Paraíba. Graduação em Enfermagem. João Pessoa, PB

Submissão: 04/05/2008

Aprovação: 3 1/08/2009

\section{RESUMO}

Este estudo teve o objetivo de descrever a vivência de familiares no cuidado da criança Que sofreu Queimadura. Foi realizado um estudo exploratório, em um hospital de emergência na cidade de João Pessoa - PB, com dez acompanhantes de crianças hospitalizadas, vítimas de Queimadura. Os resultados mostraram Que os agentes térmicos foram os maiores causadores das Queimaduras nas crianças. O discurso dos participantes revela Que a maioria dos acidentes ocorreu na presença do cuidador, menciona algumas condutas erradas após a ocorrência do acidente e alguns consideram a experiência de cuidar da criança Queimada como negativa, o Que evidencia a necessidade de orientação da população em geral e a participação no cuidar da criança Queimada.

Descritores: Cuidado da Criança; Enfermagem; Família.

\section{ABSTRACT}

This study aimed to describe the family experience in the care of the child who got burnt. An exploratory study was conducted in a hospital emergency room in the city of João Pessoa - PB, with ten companions of hospitalized burnt children. The results showed that the thermal agents were the biggest cause of children's burns. The speech of the participants shows that most accidents occurred in the presence of the caregiver, point out some wrong procedures after the accident, while some consider the experience of taking care of burnt children as negative, so highlighting the need for guidance of population as a whole and participation in the care of the burnt child.

Descriptors: Child Care; Nursing; Family.

\section{RESUMEN}

Este estudio tuvo como objetivo describir la experiencia de la familia en el cuidado de los niños que han sufrido Quemaduras. Un estudio exploratorio fue realizado en un hospital de emergencia en la ciudad de João Pessoa - PB, con diez compañeros de los niños hospitalizados por Quemaduras. Los resultados enseñaron que los agentes térmicos fueron la principal causa de Quemaduras en los niños. El discurso de los participantes indica Que la mayoría de los accidentes se produjo en presencia del cuidador, menciona algunos procedimientos equivocados después del accidente, mientras que algunos consideran que la experiencia de cuidar de los niños Quemados es negativa, destacando la necesidad de orientación para la población general y participación en el cuidado de los niños Quemados.

Descriptores: Cuidado del Niño; Enfermería; Familia. 


\section{INTRODUÇÃO}

A queimadura é problema grave, representando um dos maiores desafios dos cuidados de saúde. Junto com as alterações fisiológicas dramáticas, está o impacto do ônus financeiro gerado ao sistema de saúde e, principalmente, a familiares e vítima Que sofrem também danos emocionais. Quando a vítima é uma criança, dependendo da gravidade da Queimadura, esta pode ter prejuízo psíquico, dificuldade de crescimento ósseo, reabilitação demorada e perdas funcionais ${ }^{(1,2)}$.

Estimativas mostram Que a cada morte, outras Quatro crianças ficam com sequelas permanentes Que irão gerar, provavelmente, conseQüências emocionais, sociais e financeiras a essa família e à sociedade. De acordo com o governo brasileiro, cerca de R\$ 63 milhões são gastos na rede do Sistema Único de Saúde - SUS. Dados recentes do Ministério da Saúde apontam que 27\% dos acidentes com Queimaduras têm como vítimas crianças menores de nove anos e, Que 91,6\% dos acidentes acontecem em casa, por conta de contato com chamas, água Quente, alimentos e líquidos, o que evidencia a magnitude do problema, uma vez que na maioria das situações pode ser evitado pelo cuidador da criança e não o é, ou seja, falta prevenção ${ }^{(3)}$.

Desta forma, as Queimaduras continuam ocorrendo de forma grave, necessitando na maioria das vezes de hospitalização o Que para a criança é um grande trauma, de modo Que além do sofrimento físico, com dor intensa, associa-se o afastamento do lar, dos familiares, dos amigos, da escola, enfim, do seu meio social, passando a conviver num ambiente estranho, com pessoas desconhecidas, submetidas a procedimentos dolorosos, entre outros. Queimaduras em crianças geralmente têm repercussões sistêmicas mais críticas, tanto pela dificuldade de adaptação do organismo Quanto à desproporção da superfície corporal em relação ao peso $^{(4)}$.

Para alguns estudiosos ${ }^{(5)}$ a gravidade da Queimadura é determinada principalmente pela extensão da superfície corpórea Queimada (SCQ) e pela sua profundidade, onde também são considerados agente causal, idade, presença de problemas clínicos ou cirúrgicos simultâneos e complicações Que acompanham as Queimaduras de áreas especiais como face mãos e genitália.

Nesse sentido, a extensão de uma Queimadura em conjunto com a avaliação de profundidade indicará o procedimento terapêutico e, a classificação será leve ou peQueno Queimado, médio ou médio queimado e grave ou grande Queimado, onde os métodos utilizados para identificação da área Queimada são: regra dos nove, regra da palma da mão e o método de Lund e Browder ${ }^{(6)}$.

Há ainda outra classificação Que considera a lesão da pele descrita de acordo com a sua profundidade e é definida em termos das diversas camadas da pele atingidas. Mediante este critério, as Queimaduras podem ser classificadas nas seguintes categorias ${ }^{(7)}$ : as de espessura superficial ( $1^{\circ}$ grau) Que afetam apenas a epiderme e caracterizam-se por serem avermelhadas e dolorosas; as de espessura parcial ( $2^{\circ}$ grau), Que envolvem a epiderme e partes variadas da derme subjacente. Essas feridas formam bolhas e são dolorosas; e as de espessura total ( $\left.3^{\circ} \mathrm{grau}\right)$ Que aparecem como Queimaduras espessas, secas, esbraneuiçadas e com aspecto de couro, independentemente da raça ou coloração da pele. Nos casos graves, a pele tem uma aparência carbonizada, com trombose visível dos vasos sanguíneos. As Queimaduras de $4^{\circ}$ grau surgem como categoria atual Que, além de atingirem todas as camadas da pele, Queimam também o tecido adiposo, músculos, ossos ou órgãos internos subjacentes ${ }^{(8)}$.

A prevenção de acidentes por Queimaduras, através de divulgação de orientações, é a principal estratégia para diminuir os riscos causados pela lesão, embora, no Brasil não existam muitas campanhas voltadas para a prevenção destes acidentes, o Que resulta numa maior incidência e no aumento da morbimortalidade. Em se tratando da criança, a família é Quem fica responsável para Que exista um cuidado redobrado em torno de todos os perigos Que estejam ao seu redor, entretanto, na maioria dos casos, esta desconhece ou negligencia medidas importantes que contribuiriam para diminuir a ocorrência das Queimaduras, bem como, as condutas adeeuadas a serem adotadas caso aconteçam.

Embora os familiares sejam freqüentemente os principais fornecedores de suporte social, eles também podem se sentir sufocados pelas necessidades emocionais da pessoa desfigurada ${ }^{(9)}$. Estudos citam Que 60\% das mães apresentam distúrbios emocionais no acompanhamento de seus filhos durante e após a recuperação física. O sofrimento da mãe perdura por ver a perda permanente do corpo físico do filho ${ }^{(10)}$.

Outras pesQuisas revelam Que a família apresenta três respostas comuns ao estresse frente à Queimadura: a indecisão, a intensificação dos conflitos preexistentes e o sentimento de culpa, o que pode afetar na evolução clínica da criança diante de tais conflitos ${ }^{(10)}$. Fazem-se necessárias interação e integração do profissional, criança e família para Que o sucesso da reabilitação seja alcançado.

Nesse sentido, este trabalho se justifica pela grande relevância do papel familiar para o ajustamento da criança Queimada ao trauma da lesão, conseqüente hospitalização, e posterior fase de recuperação; é importante abordar Quais são as necessidades e as preocupações, a vivência e comportamentos dos membros da família particularmente significativos para a criança, como a mãe e o pai (ou seus substitutos), além de fornecer-lhes apoio e orientações sobre as formas adequadas de participar do cuidado à criança, a fim de atender as suas necessidades biopsicossociais.

\section{OBIETIVO}

Descrever a vivência de familiares no cuidado da criança Que sofreu Queimadura.

\section{METODOLOGIA}

Trata-se de um estudo descritivo-exploratório desenvolvido em uma unidade de tratamento de Queimados de um hospital de emergência, localizado na cidade de João Pessoa - PB. A unidade é credenciada ao Ministério da Saúde bem como é reconhecida como uma unidade hospitalar de alta complexidade.

Participaram da investigação familiares de crianças acometidas por Queimaduras Que estavam internadas na unidade de Queimados do hospital. A amostra foi composta por 10 sujeitos, os Quais foram selecionados considerando-se os seguintes critérios: ser o cuidador da criança (pai, mãe ou responsável); ter a idade mínima de 18 anos; ter convívio e estar acompanhando a criança durante a hospitalização; ter disponibilidade em participar da pesquisa, 
levando em consideração a participação voluntária no estudo após a explicação dos seus objetivos e a assinatura do Termo de Consentimento Livre e Esclarecido.

A pesquisa seguiu as observâncias éticas da Resolução 196/96 do Conselho Nacional de Saúde, principalmente no cumprimento ao Termo de Consentimento Livre e Esclarecido, Que aborda sobre a participação voluntária, confidencialidade dos dados, anonimato, desistência a Qualeuer momento da pesquisa e permissão para publicação da pesquisa. Para eue fosse possível a coleta de dados, o projeto foi encaminhado ao Comitê de Ética em Pesquisa do Centro de Ciências da Saúde da Universidade Federal da Paraíba e submetido à apreciação pelo Centro de Estudos do hospital selecionado para o estudo, recebendo aprovação em ambos os setores, o Que possibilitou a realização da peşuisa.

A coleta dos dados ocorreu por meio de um roteiro de entrevista semi-estruturado contendo Questões objetivas de identificação da amostra e subjetivas pertinentes aos objetivos do estudo. A entrevista foi realizada através da técnica de gravação conforme a aceitação do acompanhante e os dados foram posteriormente transcritos pela pesquisadora. A segunda etapa da investigação foi a coleta de alguns registros no prontuário da criança relativos às características do acidente da Queimadura e da lesão em si.

Os dados foram analisados Quanti-Qualitativamente. O achado Quantitativo contemplou a caracterização dos sujeitos através da análise dos valores absolutos e percentuais em Que se utilizou o programa Microsoft Excel, versão Windows XP. Os dados Qualitativos foram analisados através da técnica de Discurso do Sujeito Coletivo Que consiste em um conjunto de falas individuais, das Quais são retiradas as idéias centrais para a construção de um discurso síntese, Que representa o pensamento coletivo(II).

\section{RESULTADOS E DISCUSSÃO}

\section{Dados referentes às Queimaduras ocorridas nas crianças}

A Figura 1 apresenta o tipo de Queimadura e evidencia Que $80 \%$ dos casos ocorreram por exposição a objetos, líeuidos ou alimentos Quentes; 10\% ocorreram por exposição a chamas e 10\% ocorreram por choque elétrico, todos no ambiente domiciliar.

Os dados confirmam os achados da literatura Que destacam alimentos e líquidos Quentes entre os principais causadores de Queimaduras em crianças $^{(1,2)}$. Outros autores ${ }^{(12)}$ afirmam Que as crianças Que estão começando a andar são as mais frequentemente escaldadas por água Quente, e as crianças maiores têm maior probabilidade de terem sofrido Queimaduras pelo fogo.

No item profundidade das Queimaduras constata-se Que, em $90 \%$ dos casos, as Queimaduras são de $2^{\circ}$ grau, conforme apresenta Figura 2, cujo tratamento envolve a reanimação com líeuidos, o eQuilíbrio nutricional e a atenção a condições mórbidas preexistentes.

As Queimaduras de segundo grau levam cerca de três semanas para cicatrização, de forma Que a participação dos acompanhantes no cuidado faz com Que a internação não pareça ser tão longa. O envolvimento dos pais representa segurança e amor para a criança, de modo Que favorece aceitação dos cuidados por parte da mesma $^{(10)}$.

No Que se refere ao tempo de hospitalização, apresentado na Figura 3, 60\% dos pacientes passam de Quatro a sete dias porque o tratamento, no hospital onde a pesquisa foi realizada, é feito com película biológica. Esta é geralmente aplicada em Queimaduras de $2^{\circ}$ ou $3^{\circ}$ grau, protegendo a região afetada como um verdadeiro substituto da pele, o Que possibilita a formação da pele natural do paciente. Os curativos tradicionais não são considerados uma barreira bacteriana eficaz e necessitam de trocas diárias e, Quando retirados, acabam por remover a pele em formação. No caso da película biológica, Quando retirada, a Queimadura já estará em processo final de cicatrização, justificando um tempo de hospitalização relativamente maior ${ }^{(13)}$.

A Figura 4 mostra que em $60 \%$ dos casos os acompanhantes estavam presentes no mesmo ambiente onde a criança sofreu a Queimadura; mas relataram não ter conseguido impedir Que a criança fosse Queimada.

A criança é um ser vulnerável, com grandes chances de sofrer injúrias não intencionais ${ }^{(1)}$. Infelizmente, a negligência contribui para esse tipo de acidente; porém a desinformação de como prevenir Queimaduras e outras lesões é um problema Que precisa ser trabalhado.

\section{Dados pertinentes às informações do acompanhante sobre a experiência vivenciada}

O discurso do sujeito coletivo emergiu a partir das seguintes Questões norteadoras: Como ocorreu o acidente? Fale sobre a sua experiência no cuidado à criança Queimada e Que se encontra sob sua responsabilidade durante a internação hospitalar. Em sua

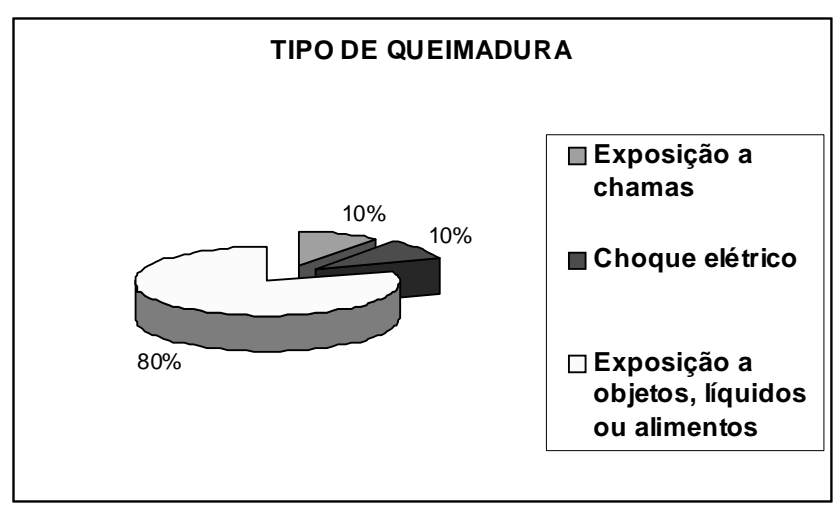

Figura 1. Distribuição percentual dos tipos de Queimaduras em crianças.

\section{PROFUNDIDADE DA QUEIMADURA}

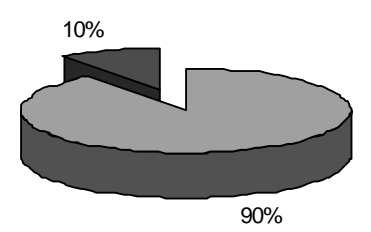

$\square 2^{\circ} \mathrm{GRAU}$ $\square 3^{\circ} \mathrm{GRAU}$

Figura 2. Distribuição percentual das Queimaduras de acordo com a profundidade da lesão. 


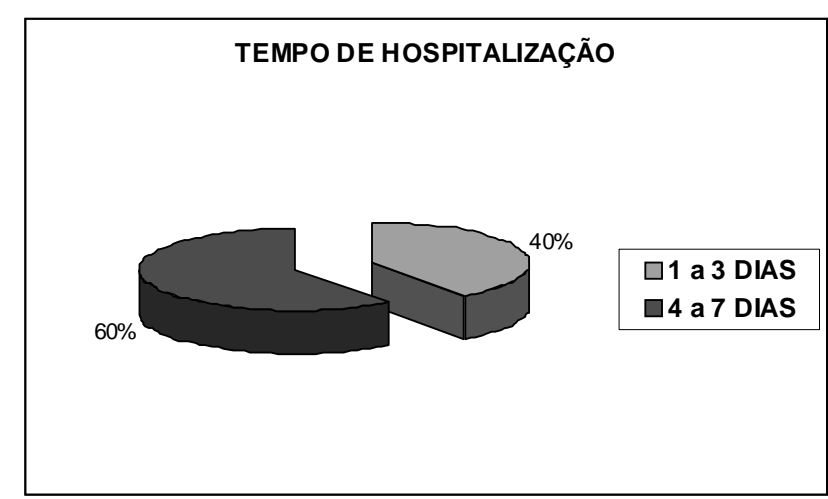

Figura 3. Distribuição do tempo de hospitalização da criança na unidade de referência.

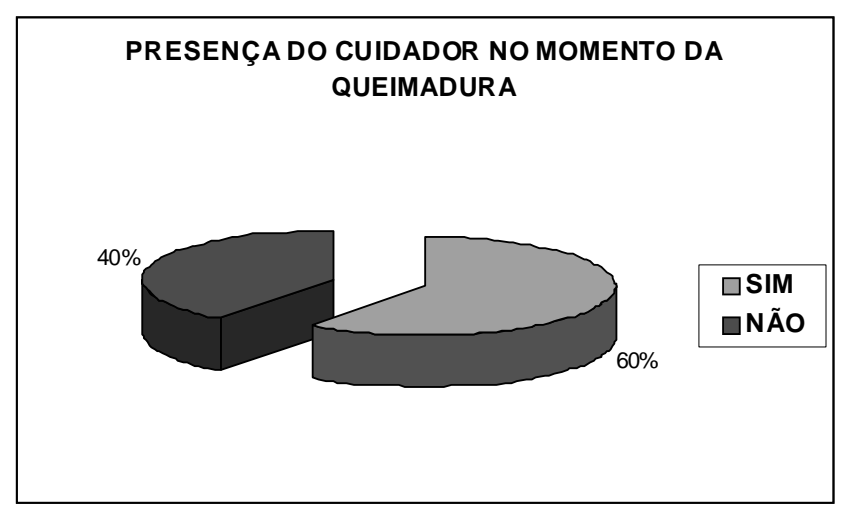

Figura 4. Distribuição percentual dos acompanhantes segundo sua presença ou não no momento da Queimadura.

opinião, o Que poderia ser feito para melhorar a condição do cuidado prestado à criança Queimada durante a internação no hospital?

A análise do DSC será apresentada conforme apresentação das Questões.

\section{Questão 1: Como ocorreu o acidente?}

A análise do DSC dá origem à idéia central: exposição a chamas, objetos e líquidos quentes e por choque elétrico.

Os participantes confirmam os agentes térmicos (exposição a objetos, alimentos e líquidos Quentes) como causadores das Queimaduras, observando-se um componente novo, implícito nos discursos, Que é a falta de cuidado dos acompanhantes, o Que acaba ocasionando o acidente, conforme discurso dos participantes abaixo:

[...] Ela atravessou a cerca e passou por debaixo do arame e Queimou o pé no fogo. [...] aí ele colocou o dedo lá no fio e Queimou o dedo dele todinho.|... o o bebê pegou uma cuscuzeira Que estava em cima do fogão e Que tinha acabado de sair do fogo, com cuscuz dentro dela e puxou; aí pegou logo nas costas dele [.] Ele pegou o ferro e colocou em cima da mão. [... Minha filha colocou o prato em cima do sofá, aí ela veio e o prato virou na perninha dela. [...J Eu deixei o prato Quente em cima da mesa e me virei para pegar o pão Quando, de repente, o prato tinha caído por cima dela [...] Eu deixei um copo de café Quente em cima da mesa; com poucos minutos ela pegou o copo e aí derramou.

Entretanto, destaca-se o caráter não-intencional dos acompanhantes, como é o caso da falta de previsibilidade das possíveis consequências de uma atitude de descuido que resulte em acidente. Supõe-se Que a falta de conhecimento de medidas simples, voltadas para a prevenção de Queimaduras, é responsável pelos acidentes, sendo sua adoção imprescindível para evitá-las.

Referindo-se às Queimaduras causadas por alimentos ou líeuidos Quentes, algumas medidas preventivas são recomendadas como: redução do aQuecedor de água para uma temperatura de $49^{\circ} \mathrm{C}$. Além disso, a água do banho deve ser verificada antes Que a criança seja imersa nela, os cabos de utensílios de cozinha devem ficar voltados para a parte posterior do fogão. Quando a criança está no chão, o derramamento de líquidos Quentes ou de óleo Quente é evitado. As toalhas de mesa, penduradas, também são tiradas do alcance da criança, a fim de evitar o derramamento de objetos aQuecidos e Que estejam em cima da mesa ${ }^{(12)}$.

No que diz respeito ao choque elétrico, também presente no discurso das entrevistadas, as medidas preventivas incluem Que as tomadas elétricas devem ser cobertas com capas protetoras de plástico para impedir Que a criança segure ou coloque objetos, tais como grampos, dentro das tomadas. Os fios ligados devem ser colocados fora do alcance delas, de modo Que as crianças curiosas não possam mastigá-los e romper o seu revestimento de borracha. As crianças não devem brincar próximo a aparelhos de televisão, aparelhos de som ou outros aparelhos, caso estas unidades sejam de ligar e desligar; as crianças não conseguem determinar o Quanto o aparelho é seguro. Porém, na ocorrência deste, deve agir interrompendo o processo de Queimadura e transportar a criança imediatamente para a instituição de saúde mais próxima para o tratamento definitivo e a avaliação Quanto à transferência para um centro de Queimados(I).

Questão 02: Quais as condutas adotadas e por Quem?

A análise do DSC dá origem à ideia central: coloquei água, clara de ovo, pasta de água, procurei o posto de saúde.

O discurso dos participantes relata as condutas realizadas pelos acompanhantes no momento da Queimadura. Em alguns caso, os acompanhantes tomaram a medida correta; em outros, não, conforme falas apresentadas:

[...] Eu molhei com água eu e minhas irmãs. [...] Quando eu cheguei à noite e vi, eu pedi a minha filha para levar ela no postinho, aí lá disseram que era caso pra aqui [... I Na hora me ensinaram clara de ovo, aí eu coloquei, mas aí depois a gente ligou para o SAMU aí eles disseram que eu ficasse lavando com água, enQuanto eles chegavam [...] Lavei só com água . [...] Eu dei um banho nele só com água e coloquei pasta d'água nele.[...] Na hora eu só passei uma pomada Que tinha lá para dor.

Dentre as atitudes corretas, citam-se dar banho na criança e lavar o ferimento só com água. Com relação às atitudes incorretas, destacam-se molhar com água gelada, usar pomadas, clara de ovo e pasta de água.

A recomendação correta é usar água em temperatura ambiente para lavar o ferimento e ligar para o serviço de emergência mais 
próximo, seguindo as orientações até chegar à unidade de emergência. Também se referindo às condutas, em relação aos cuidados com as Queimaduras, o mesmo autor refere que pomadas tópicas e antibióticos tópicos convencionais não devem ser aplicados porQue eles impedem a inspeção direta da Queimadura ${ }^{(8)}$.

Questão 03: Fale sobre a sua experiência no cuidado à criança Queimada e Que está sob sua responsabilidade, durante a internação hospitalar.

A análise do DSC deu origem a duas ideias centrais:

Ideia central 0I: é muito ruim, eu não Quero passar por isso nunca mais.

Ideia central 02: o meu papel aQui é muito importante.

Com relação à experiência no cuidado à criança Queimada e sob sua responsabilidade, observa-se, nos discursos acima, na ideia central 01, Que os acompanhantes concebem a experiência negativamente, não desejando mais passar por ela.

[...] é muito ruim, e eu não Quero passar por isso nunca mais.

[...] Eu e minha filha ficamos aperreadas porque o bracinho dela ficou todo queimado. [...] Eu não Quero passar por isso nunca mais; é horrível [...] Eu fiquei doidinha; é ruim demais passar por isso. [...].

As falas dos sujeitos não surpreendem uma vez Que a Queimadura/internação da criança os leva a vivenciar o sofrimento da mesma, o Qual é amplamente duro para eles do ponto de vista humano, e, sobretudo, parental; associado à falta de condições adequadas para o acompanhante no hospital, ao afastamento do lar, dos cônjuges, de outros filhos; enfim, do seu meio familiar e social.

Entretanto, este sentimento de aversão deve ser trabalhado pela equipe. Muitas vezes é necessária a participação de um profissional especializado na área de saúde mental, o Qual possa dar suporte nessas situações, fortalecendo o vínculo família-criança, de modo Que a assistência se torne mais humana, e a hospitalização não pareça tão difícil para a criança e o cuidador. Quando a ansiedade se mantém elevada, o manejo do paciente se torna mais difícil ${ }^{(10)}$.

$\mathrm{Na}$ idéia central 02 , do DSC 02 , observa-se que a maioria dos acompanhantes se acha importante no cuidado à criança, uma vez Que ela se encontra indefesa e incapaz de cuidar-se sozinha.

[...] O meu papel aqui é muito importante porque ela não fica sem mim, se eu sair ela fica chorando. [...] Eu estou sendo importante para ela, porQue ele sempre solicita a minha presença [...] É importante a minha presença porque ele é muito novinho e fica sofrendo porQue ele não sabia o Que estava fazendo; porQue se ele soubesse, ele não tinha colocado a mãozinha lá.

Essas falas reforçam a dependência das crianças, Que devem de ser cuidadas pelos adultos, tanto mais Quanto menor for a sua idade, o Que, certamente, se reflete também na prevenção de acidentes, e que deve ser repassada aos pais através de campanhas educativas. Deve-se ressaltar Que, em cada faixa etária, a criança apresenta maior suscetibilidade a determinados tipos de acidentes, os Quais devem ter enfoeue específico. Neste aspecto, crianças menores de 5 anos de idade estão em grande risco de Queimaduras, devido à sua pele fina, demora de reação, pouca agilidade e grande curiosidade ${ }^{(14)}$.

Questão 04: Em sua opinião, o Que poderia ser feito para melhorar a condição do cuidado prestado a criança Queimada no hospital?

Ideia central 01 : não precisa melhorar em nada.

Ideia central 02: só na parte da alimentação

$\mathrm{Na}$ ideia central 01 , evidenciada no DSC 01 , percebe-se a satisfação das acompanhantes com a assistência recebida, inclusive excluindo a necessidade de melhorias neste sentido.

[...] Está tudo bem, não precisa melhorar em nada. [...] Não tenho nenhuma reclamação a fazer, eu gostei muito daQui. [...] Não estou achando nada ruim, não. [...] Está tudo bem. [...] Ele já é grandinho, não dá muito trabalho não.

Por outro lado, na ideia central 02 , observa-se a insatisfação com a alimentação; porém com a ausência de propostas para melhorar.

[...] só na parte da alimentação Que pela manhã ela come papinha e à noite ela janta sopinha e aqui está diferente. [... I Às vezes, eles dizem Que vão trazer o mingau de três em três horas e não trazem.

Diante desses dados, percebe-se a necessidade de aprofundar o estudo, uma vez Que, por se tratar de um hospital público, alvo de problemas e carências amplamente divulgadas, através dos meios de comunicação, é de se conceber Que existam outras lacunas passíveis de melhoria e Que não foram identificadas nesta pesQuisa. É possível que muitos problemas vivenciados pela equipe de saúde (como falta de recursos materiais, humanos, baixos salários, falta de motivação etc), tenham afetado a Qualidade da assistência, sendo esta motivo de insatisfação para os usuários da Unidade de Tratamento de Queimados da Instituição.

\section{CONCLUSÃO}

A pesquisa revela Que as mães caracterizam a experiência de cuidar da criança como negativa, o Que não surpreende pelo fato de o cuidador estar vivenciando o sofrimento da criança e por estar distante do meio familiar e social. Poucos revelaram insatisfação com o serviço, com exceção à referência ao item alimentação das crianças internadas; porém, uma análise mais aprofundada desta Questão, envolvendo inclusive pesQuisas junto aos profissionais de saúde, poderá revelar dificuldades e sugestões para melhorar, cada vez mais, a Qualidade da assistência a essa clientela.

Acredita-se Que este estudo contribua com mais esclarecimentos sobre a problemática das Queimaduras em crianças, sobretudo no Que diz respeito à prevenção, alertando os profissionais de saúde e educadores e as diversas instâncias da sociedade e do Governo, uma vez Que não podemos deixar Que as estatísticas aumentem, já Que a maioria dos registros está relacionada a causas passíveis de prevenção. 


\section{REFERÊNCIAS}

1. Paes CEN, Gaspar VLV. As injúrias não intencionais no ambiente domiciliar: a casa segura. J Pediatria, 2005; 81 (Supl 5): 146-54.

2. Martins CBG, Andrade SM. Queimaduras em crianças e adolescentes: análise da morbidade hospitalar e mortalidade. Acta Paul Enferm 2007; 20(4): 464-9.

3. Agência Brasileira de Notícias. 91\% das Queimaduras em crianças ocorrem em casa. Brasília: ABN; 2009. [citado em: 09 mar 2009]. Disponível em: URL: http://www.abn.com.br/ index.php.

4. Vale ECS. Primeiro atendimento em Queimaduras: a abordagem do dermatologista. An Bras Dermatol 2005; 80(1): 9-19.

5. Knobel E, Laselva CR, Morais Júnior DF. Terapia intensiva: Enfermagem. São Paulo: Atheneu; 2006.

6. Menezes EM, Silva MI. A Enfermagem no Tratamento dos Queimados. São Paulo (SP): EPU; 1988.

7. Morton PG. Cuidados críticos de enfermagem: uma abordagem holística. 8a ed. Rio de Janeiro: Guanabara Koogan; 2007.

8. National Association of Emergency Medical Technicians. Atendimento pré hospitalar ao traumatizado: Básico e avançado. Rio de Janeiro (RJ): Elsevier; 2007.
9. Rossi LA. O processo de cuidar da pessoa Que sofreu Queimaduras: significado cultural atribuido por familiares. Rev Esc Enferm USP 2001; 35(4): 336-45.

10. Ferreira LA. Ser-mãe-no-mundo com filho Que sofreu Queimaduras: um estudo compreensivo [tese]. Ribeirão Preto: Escola de Enfermagem de Ribeirão Preto, Universidade de São Paulo; 2006.

11. Lefévre F, Lefévre, AMC. O discurso do sujeito coletivo: um novo enfoque em pesquisa Qualitativa (desdobramentos). $2^{\text {a }}$ ed. Caxias do Sul: Educs; 2005.

12. Whaley LF, Wong DL. Enfermagem Pediátrica: elementos essenciais à intervenção efetiva. $3^{\mathrm{a}}$ ed. Rio de Janeiro: Guanabara-Koogan; 1997.

13. Osman SA, Souza FC, Dolci JE. Estudo experimental sobre a aplicação de película de celulose (bionext ${ }^{\circledR}$ ) em área cruenta de ressecção de concha nasal de coelhos. Acta ORL 2007; 25 (4): 304- II.

14. Oliveira Filho EA. Incêndios e Queimaduras: prevenção de acidentes. Disponível em: http://www.abcdasaude.com.br/ artigo.php?252 